\title{
A Multidisciplinary Undergraduate Nanotechnology Education Program with Integrated Laboratory Experience and Outreach Activities
}

\section{Dr. Priscilla J Hill, Mississippi State University}

Priscilla Hill is currently an Associate Professor in the Dave C. Swalm School of Chemical Engineering at Mississippi State University. She has research interests in crystallization, particle technology, population balance modeling, and process synthesis. Her teaching interests include particle technology, nanotechnology, and separations.

\section{Prof. Brenda Lee Kirkland, Department of Geosciences, Mississippi State University}

Brenda L. Kirkland received undergraduate degrees in German (BA) and in Geology (BS) from the University of Texas at Austin. She spent the academic year 1982-83 at Ludwig-Maximillans University in Munich, Germany with a stipend from the Federation of German-American Clubs and a Fulbright travel grant. She earned an MS in geology at Texas A\&M University and Ph.D. in geology with a minor in botany from Louisiana State University. She began as an Assistant Professor at the University of Texas at Austin in 1992 and moved to Mississippi State University in 2000. She was granted the Mississippi State University Faculty Diversity award in 2015 and the American Association of Petroleum Geologists Distinguished Educator Award in 2016.

\section{Prof. Yaroslav Koshka, Mississippi State University}

Dr. Yaroslav Koshka received his B.S. and M.S. in Electronics from Kiev Polytechnic University in Kiev, Ukraine. He received his Ph.D. in Electrical Engineering in 1998 from the University of South Florida, Tampa, FL. From 1993 till 1995, Dr. Koshka worked as an engineer mathematician at the Institute for Problems of Material Science, Kiev, Ukraine. From 1998 to 2000, he was a postdoctoral fellow at Mississippi State University (MSU). In 2000 he accepted a position as an assistant research professor at the same university. He joined the faculty at MSU in 2002. He is currently a professor in the Department of Electrical and Computer Engineering at MSU and the director of the Emerging Materials Research Laboratory. His research interests include semiconductor materials and device characterization, defect engineering, synthesis of wide-bandgap semiconductor materials, physics of semiconductor devices, nano-electronics and machine learning for materials sciences.

\section{Dr. Rani W. Sullivan, Mississippi State University}

Dr. Rani Warsi Sullivan is an Associate Professor of Aerospace Engineering at Mississippi State University. Dr. Sullivan has teaching and research interests in the area of solid mechanics, aircraft materials and structures, and engineering education. Current research includes fiber optic strain sensing for development of an in-flight structural health monitoring system, characterization of the time-dependent deformation of polymer nanocomposites, and strength and vibration testing of full scale composite air vehicles.

\section{Dr. Tonya W. Stone, Mississippi State University}

Tonya Stone is an assistant professor of mechanical engineering at MSU. Her research interests include multiscale materials modeling, mechanical behavior and characterization of materials, and modeling of nanomechanics/nanomaterials. 


\title{
A Multidisciplinary Undergraduate Nanotechnology Education Program with Integrated Laboratory Experience and Outreach Activities
}

\begin{abstract}
In recognition of the global, national, and local importance of nanotechnology, a diverse team of educators and researchers are developing a multidisciplinary nanotechnology educational program with support from a National Science Foundation (NSF) Nanotechnology Undergraduate Education (NUE) in Engineering award. A previous NSF NUE grant resulted in the development of lecture courses and course modules, but lacked hands-on experiments and computer simulation exercises. The goal of this program is to address this deficiency by incorporating new laboratory and simulation modules into existing classes, and by developing a new nano/micro laboratory course. One novel aspect of this program is that it is coordinated across two colleges and includes faculty in aerospace, chemical, electrical, and mechanical engineering as well as geological sciences. This program includes outreach activities for students in grades $5-12$ through an existing NanoClub. Outreach also includes tours of the Institute for Imaging and Analytical Technologies $\left(\mathrm{I}^{2} \mathrm{AT}\right)$, an on-campus facility that emphasizes nanotechnology during demonstrations of confocal, atomic force, and electron microscopes.

Current results from this program that started in January 2014 are presented including a discussion of progress with a focus on new developments since January 2015. These include course modules developed, outreach activities through the NanoClub, student enrollment, and the diversity of the students impacted by these courses.
\end{abstract}

\section{Introduction}

In many colleges and universities, engineering and science departments have started including instruction in nanoscience and nanotechnology through new nanotechnology courses and through incorporating nanotechnology modules in existing courses. A similar approach was taken at Mississippi State University ${ }^{1-3}$, but it was soon realized that the program lacked the laboratory experiments and computer simulations that are needed ${ }^{4}$. Therefore, a group of faculty from various fields in engineering and science are addressing this lack of hands-on nano-education activities. Support for this work is being provided from NSF through a Nanotechnology Undergraduate Education (NUE) grant.

This project started in January 2014. Because the first year's activities have already been reported $^{5}$, this paper reports on activities and progress made in 2015 . This includes new course development, development and implementation of new nanotechnology modules in multiple departments, and outreach to K-12 students.

\section{New Courses}

The special topic course, ECE 4990-01/6990-01, Special Topic in ECE - Bio-nano-electronics, a split level technical elective, was developed further by Dr. Koshka. This is a three credit hour 
course on electrical/electronics engineering for the biomedical field including the following topics: overview of the human cell structure, nerve cells and neuron signaling, the latest developments in nano-fabrication, bio-sensors, nano-medicine, and neuro-electronic interfacing. It was a challenging but interesting experience trying to give students, who had had almost no formal education in biology-related disciplines, sufficient background for understanding selected examples of bio-electronic devices, such as sensors, based on a number of different transduction principles relevant for electronics engineers. Another interesting deviation from the students' comfort zone was in the topics selection for the broad area of nano-fabrication. Typically, many ECE students discover in prior classes that their educational backgrounds make it relatively natural to study semiconductor/electronics fabrication techniques aimed at very large scale integration (VLSI) used in modern integrated circuit (IC) process technology. The same students seem to find it more challenging, but also more interesting, to face prioritization of certain fabrication techniques that appear to them more exotic in the context of their prior education.

\section{Nanotechnology Modules}

A new nanotechnology module was implemented by Dr. Koshka in ECE 4293-01/ 6293-01, Nano-electronics in the spring 2015 semester. This split-level technical elective was populated by 1 graduate and 8 undergraduate students. The Medici 2D Device Simulator from Synopsis was used in 2014 to develop templates of simulation scripts for modeling performance of micro/nano-electronic devices to be covered in this class. In this course, limited-scope simulation assignments were given to the students as an experiment. Such assignments were not present in the previous offerings of this course. Graduate students in the ECE 4293-01/ 6293-01, Nanoelectronics course were better prepared to learn the new nano-electronics device simulation tool and achieve quick progress. However, simulation assignments like that (if carefully structured) were found very much doable also for the UG students. Such simulation assignments/labs will be made an important part of student progress monitoring and grading in future offerings of this course.

A new course module was developed and implemented by Dr. Kirkland for GG 1113 Introduction to Earth Science I. The goals of this module were to introduce students to nanometer scale features in nature and give them an opportunity to participate in research. The students in this introductory class were predominantly taking it as a science elective and were not majoring in a STEM field. The module included a lesson on scale, nanometer-scale features in nature and a hands-on participation exercise. Students compared images of laboratory-generated nanometer-scale textures to images from nature, including Martian meteorite, calcified arterial tissue, and hot spring deposits. The students clearly enjoyed the module more than traditional lectures. In preparation for this module a series of precipitation experiments were carried out by one graduate student, two undergraduates and a faculty member. Images developed and implemented for GG 1113 Introduction to Earth Science I were presented in two poster sessions and one talk ${ }^{6-8}$.

A nanotechnology course module was created and taught by Dr. Sullivan for EM 4133/6133 Composite Materials, a split-level course. The class had a total of 11 undergraduate and 2 graduate students in the spring 2015 offering of this course. Excerpts from a review article about the vibration properties and behavior of carbon nanotubes (CNTs) and nanocomposites 
were assigned for class discussion ${ }^{9}$. This article was selected as it presented an overview of CNT physical characteristics, applications and challenges. Regarding nanoparticles, carbon nanotubes and nanocomposites, a pre-survey was given to the students. A self-evaluation revealed that $58 \%$ of the students felt that they had a low level of knowledge and $17 \%$ felt they had no knowledge about nanotechnology. In the self-evaluation, 25\% of the students indicated a high level of interest and 58\% indicated a moderate level of interest in nanocomposites. The pre-survey was also used to assess basic knowledge regarding fundamental characteristics and physical properties of carbon nanotubes and nanoparticles; an average score of 64/100 was obtained. Students participated in a class discussion regarding the journal article and the unique characteristics of nanocomposites and their constituents. These were compared to traditional polymer matrix composites. Student engagement and participation in the classroom discussion demonstrated an increase in student interest as well as knowledge in nanotechnology.

The introductory freshman seminar course, NanoExposed!, was co-taught by Hill, Koshka, Stone, and Kirkland for the sixth time during the Fall 2015 semester to a class of 43 freshmen, 1 sophomore, and 2 juniors. This course included a geosciences lecture on nanometer-scale textures in carbonate minerals; and the next two sessions were a tour of the $\mathrm{I}^{2} \mathrm{AT}$ facility, the core imaging facility on campus. New demonstrations were developed and implemented by Dr. Stone in 2015. For example, the effect of increasing surface area was demonstrated by adding the same amount of colored water to two graduated cylinders, and then adding a whole antacid tablet to one cylinder and a crushed tablet to the other cylinder. The result was that the level in the cylinder with the crushed tablet was significantly higher than the level in the cylinder with the whole tablet, demonstrating the effect of increased surface area.

\section{Outreach Activities}

The Nano Club, a bi-weekly afterschool outreach program at the local Boys and Girls Club of Starkville, was created in 2011 by Dr. Tonya Stone, an Assistant Professor in Mechanical Engineering at Mississippi State University. The main objectives of the Nano Club are to provide underrepresented students in grades 5th -7 th a fun, activity-based learning atmosphere where they can learn about nanotechnology, and to expose student members to science and engineering research in general. During 2015, the weekly outreach activities were led by undergraduate research assistants, BreAnna Pittman and Patrick King, and a team of MSU underrepresented engineering student volunteers (Patrick Christian, Sydney Terry, and Gaybriel Carter) who also served as mentors to the Nano Club students.

Some of the favorite NanoClub activities included introducing students to nanotechnology terminology, having the students measure and compare their heights in nanometers, exploring the size of a single string of human hair, of fleas, and of dust mites, conducting a crime scene investigation using microscopes to study hair and fingerprint analyses, and learning about projectile motion through a life-size Angry Birds game. In addition, EcoCar volunteers and the MSU Robotics Team also visited the Nano Club to lead the students in activities on constructing an egg tower activity out of straws to learn about structural design and on building a simple machine using household items, respectively. 
In Summer 2015, Nano Club hosted a Nano Camp open to all students enrolled at the Boys and Girls Club. Forty students registered for the two day event, which included 20 students from 2nd - 4th grades and 20 students from 5th - 12th grades. The NanoClub leaders led hands-on activities that explored nanotechnology during the camp. The younger students made ultraviolet bracelets to learn about the different wave lengths of light and built gum drop molecules. The older students explored the hydrophilic and hydrophobic properties of regular sand versus "nano" sand. In addition, the 5th - 12th grade students took a field trip to the Institute for Imaging \& Analytical Technologies $\left(\mathrm{I}^{2} \mathrm{AT}\right)$ center at MSU where they were given demonstrations on the different instrumentation used for nanotechnology research (AFM, SEM, TEM, confocal microscope). The students wrapped up their field trip with a tour of the laboratories at the Center for Advanced Vehicular Systems where they learned about on-going research projects through demonstrations on the Bagley Engineering Car of the Future, the EcoCar competition, large diesel engines, the driving simulator, powder metallurgy compaction using an Instron electromechanical testing system, and robot design for search and rescue efforts. Current updates on the Nano Club outreach program are available on Facebook (Starkville NanoClub) and Instagram (@starkville_nanoclub).

The Institute for Imaging \& Analytical Technologies on campus offers tours of its facilities as well as instrument demonstrations. These instruments include confocal, atomic force, and electron microscopes. In connection with this NUE program, recent tours emphasized how these instruments allow researchers to observe structures at the nanoscale. For 2015, $\mathrm{I}^{2} \mathrm{AT}$ outreach included tours for 200 students in the 4th through 12th grades, for 225 students from community colleges, for 117 students enrolled in classes at MSU, and 41 other college students from other colleges through programs such as the REU program.

\section{Student Enrollment and Diversity}

One goal of the NanoExposed! class was to introduce nanotechnology to entering students from a variety of academic majors. In 2015, the course was populated by 46 students from a range of majors including aerospace, biological, chemical, computer, mechanical, petroleum, and software engineering; and biochemistry, biological sciences, chemistry, computer science, microbiology, and pre-accounting. Students from underrepresented minorities included 10 female students (21.7\%), 2 African-American students (4.3\%), 3 Hispanic/Latino students (6.5 $\%)$, and 2 students from other minorities $(4.3 \%)$.

The ECE 4293-01/ 6293-01, Nano-electronics, was taken by 9 students ( 8 undergraduate and 1 graduate level). These students included 1 Asian student and 1 female student.

The Nano Club had 13 student members in Spring 2015 (7 females, 6 males), and 20 student members in Fall 2015 (14 females, 6 males). The average number of students participating at the bi-weekly meetings during the fall semester was 12 female and 4 male students. In Summer 2015, Nano Club hosted a Nano Camp open to all students enrolled at the Boys and Girls Club. Forty students registered for the two day event, which included 20 students from 2 nd - 4th grades and 20 students from 5 th -12 th grades.

\section{Goals and Results}


The specific goals for this project for the second year were to: (1) develop new nanotechnology modules for existing courses, and teach the freshman nanotechnology seminar; (2) include students from underrepresented minorities in the courses; (3) disseminate results; and (4) prepare for new nanotechology courses. The specific objectives were met by 1) offering the freshman seminar and teaching new nanotechnology modules in Nano-electronics, Introduction to Earth Sciences I, and Composite Materials courses; 2) including students from underrepresented minorities in these classes as described in the section on student enrollment and diversity; 3 ) presenting a poster paper at the national ASEE conference ${ }^{5}$, and presenting geology images in two posters and one talk; and 4) preparing for new nanotechnology courses by ordering supplies and performing preliminary experiments.

\section{Acknowledgment}

This material is based upon work supported by the National Science Foundation under Grant No. 1343708.

\section{References}

1. Hill, PJ, Koshka, Y, Myers, OJ, Henington, CD, Thibaudeau, G. Multidisciplinary Undergraduate Nanotechnology Education at Mississippi State University, Journal of Nano Education, 2013; 5: 124-134.

2. Hill, PJ, Koshka, Y, Myers, OJ, Thibaudeau, G. Henington, CD. NanoExposed! - An Introduction to Nanotechnology. 2012 ASEE Annual Conference \& Exposition, San Antonio, June 2012.

3. Hill, PJ, Koshka, Y, Myers, OJ, Thibaudeau, G. Henington, CD. A Multidisciplinary Undergraduate Nanotechnology Education Program. 2013 ASEE Annual Conference \& Exposition, Atlanta, June 2013.

4. Chopra, N, Reddy, RG. Undergraduate education in nanotechnology and nanoscience. The Journal of the Minerals, Metals \& Materials Society, 2012; 64: 1127-1129.

5. Hill, PJ, Koshka, Y, Stone, TW, Kirkland, BL, Sullivan, RW, A Multidisciplinary Undergraduate Nanotechnology Education Program with Integrated Laboratory Experience. 2015 ASEE Annual Conference \& Exposition, Seattle, June 2015.

6. Testa, MP, Kirkland, BL, Attempting to identify spheroidal structures found at the base of aragonitic botryoids. Geological Society of America Meeting in Baltimore, Maryland, November 2015.

7. Testa, MP, Kirkland, BL, Vincent-Couture, M, Exploration of the relationship between microbial dendritic shrub structures and formation of aragonitic botryoidal cement. 15th Bathurst Meeting, Edinburgh, UK, July 2015.

8. Kirkland, BL, Testa, MP, Rider, ME, Vincent-Couture, M, George, JW, Folk, RL, Attempts at imaging the interface between organic matter and calcium carbonate: journeys at the nanometer-scale. 15th Bathurst Meeting, Edinburgh, UK, July 2015.

9. Gibson RF, Ayorinde EO and Wen Y-F. Vibrations of carbon nanotubes and their composites: A review. Composites Science and Technology. 2007; 67: 1-28. 